\author{
Andrew J Ghio \\ Mary Ann Bassett \\ Debra Levin \\ Tracey Montilla
}

\section{Suplemento de oxigénio necessário em voluntários saudáveis quando submetidos a broncoscopia com lavado broncoalveolar}

\section{Oxygen supplementation is required in healthy volunteers during bronchoscopy with lavage}

\section{Resumo}

A hipoxemia pode complicar a broncoscopia, limitando a utilidade e realização da técnica.

As causas mais frequentes de hipoxemia durante a broncoscopia são a doença pulmonar subjacente, a obstrução das vias aéreas, o pneumotórax, a hemorragia secundária e a biópsia pulmonar transbrônquica ou outro procedimento broncoscópico, a sedação exagerada e o broncoespasmo.

Os autores decidiram testar o postulado de que a broncoscopia com lavado broncoalveolar precisa de oxigénio suplementar em voluntários saudáveis submetidos ao exame.

Todos os voluntários demonstraram não ter sintomas respiratórios e que o exame objectivo e a avaliação da função pulmonar eram normais. A broncofibroscopia foi realizada sem sedação e não foram efectuadas biópsias. Antes da broncoscopia, foi colocada uma sonda nasal na narina oposta à do bron- cofibroscópio. Seis voluntários foram submetidos a oxigenioterapia a $2 \mathrm{~L} / \mathrm{min}$ e seis voluntários não foram sujeitos a oxigenioterapia. Depois de iniciar a técnica, assim que a saturação fosse igual ou inferior a $90 \%$ aumentava-se o suplemento de $\mathrm{O}_{2}$. Os autores verificaram que todos os voluntários não submetidos a oxigenioterapia necessitaram de suplemento de oxigénio na mesma fase do procedimento técnico, em contraste com os voluntários que iniciaram a broncoscopia com $\mathrm{O}_{2}$, que não revelaram nunca hipoxemia. A dessaturação de $\mathrm{O}_{2}$ nos voluntários que efectuaram a broncoscopia sem $\mathrm{O}_{2}$ a hipoxemia começou sempre quando se iniciou o lavado broncoalveolar.

Os autores, perante a análise deste grupo, concluíram que a administração de $\mathrm{O}_{2}$ suplementar nos doentes submetidos a broncoscopia deve ser uma regra, pois pode minimizar as complicações relacionadas, particularmente com a hipoxemia.

J Bronchol 2007; 14:19-21. 


\section{Comentário}

É sabido que a hipoxemia é uma das complicações frequentes da broncofibroscopia e que pode limitar a realização da mesma e alguns procedimentos invasivos.

A nossa experiência permite-nos constatar que são muitos os doentes que vêm a necessitar de suplemento de $\mathrm{O}_{2}$ durante a técnica ou depois da realização da mesma.

Avaliando os resultados dos autores, apesar de se tratar de um estudo preliminar e com uma amostra pequena, defende-se o suplemento de $\mathrm{O}_{2}$ durante o exame, nos doentes submetidos a broncofibroscopia, particularmente quando tem indicação de realização de lavado broncoalveolar.

$\mathrm{O}$ suplemento $\mathrm{O}_{2}$ evita a dessaturação e subjacente hipoxemia, minimizando a ocorrência de complicações mais frequentes, como arritmias, insuficiências respiratórias graves com eventual necessidade de ventilação não invasiva e/ou invasiva. Pensamos que a decisão de fazer $\mathrm{O}_{2}$ suplementar durante a broncofibroscopia também é suportada pela avaliação prévia da função respiratória.

Analisando o artigo em causa, e baseados na nossa experiência, o consenso final pode ser a indicação de $\mathrm{O}_{2}$ suplementar em todos os doentes que vão ser submetidos a broncofibroscopia com lavado broncoalveolar, mesmo com uma função respiratória e saturação de $\mathrm{O}_{2}$ prévio normal.

\section{Mensagem}

- A hipoxemia pode complicar a broncoscopia, limitando a utilidade da técnica.

- A função respiratória e gasimetria arterial não são aspectos preditivos de não haver necessidade de oxigénio suplementar durante a broncofibroscopia.

- A oxigenoterapia suplementar durante a broncofibroscopia, particularmente quando é indicação com a realização do lavado broncoalveolar, deve ser obrigatória.

\section{Bibliografia}

American Thoracic Society. Diagnostic standards and classification of tuberculosis in adults and children. Am J Respir Crit Care Med 2000; 161: 1376-95;

Baughman RP. Use of bronchoscopy in the diagnosis of diagnosis of infection in the immunocompromized host. Thorax 1994; 49:3-7;

Bell D, Leckie V, McHendrick M. The role of induced sputum in the diagnosis of pulmonary tuberculosis. $\mathrm{J}$ Infect 2003; 47:317-21;

Dickson S, Brent A, Davidason R, et al. Comparison of bronchoscopy and gastric washing in the investigation of smear-negative pulmonary tuberculosis. Clin Infect Dis 2003; 37:1649-53;

Eisenach KD, Sifford MD, Cave MD, et al. Detection of mycobacterium tuberculosis in sputum samples using a polymerase chain reaction. Am Rev Respir Dis 1991; 144:1160-3.

J Rosal Gonçalves 07.03.08 